\title{
Zunächst gilt es, die Zellentwicklung komplett nachzuvollziehen
}

\section{Welche Optionen gibt es, Stammzellen in der Therapie bei Diabetes mellitus einzusetzen? Dies und mehr wurde beim „,Islet Workshop AKROBAT*“ von internationalen Forschern erörtert. Auch wenn der große Durchbruch aufgrund der Komplexität der biologischen Prozesse noch nicht gelungen ist, schreitet die Betazellforschung voran.}

Diabetes mellitus ist durch den völligen (Typ 1) oder partiellen (Typ 2) Verlust der Insulin produzierenden Betazellen in Langerhans-Inseln (Abb.1, Alfazellen Abb. 2) des Pankreas charakterisiert. Die klinische Betazellersatztherapie bietet aktuell zwei Optionen: die Transplantation eines Pankreas oder die Infusion von isolierten Inseln via Pfortader in die Leber. Allerdings ist eine nebenwirkungsreiche Immunsuppression nötig, weshalb meist nur Typ-1-Diabetiker transplantiert werden, die aufgrund schwerer diabetischer Komplikationen eine neue Niere erhalten haben und bereits immunsupprimiert sind.

\section{Wichtig: Forschung zur Pankreasentwicklung} Die begrenzte Verfügbarkeit von passenden Spenderorganen initiierte die Idee, Betazellen in vitro aus embryonalen Stammzellen und adulten Vorläuferzellen wie mesenchymale Knochenmarkstromazellen (MSC) zu generieren. Dies gelingt zwar inzwischen besser als noch vor einigen Jahren, doch fehlt den in vitro generierten Phänotypen meist eine physiologische Insulinsekretion oder die Zellen können nicht ausreichend vermehrt werden. Forscher gehen heute davon aus, dass die erfolgreiche Herstellung von Betazellen erst möglich ist, wenn man die Embryonalentwicklung des Pankreas versteht und nachahmen kann. Vor diesem Hintergrund untersucht Dr. Francesca Spagnoli vom MDC Berlin das komplexe und konzertierte An- und Ausschalten von Genen während der Pankreasentwicklung. Da Pankreas und Leber aus einem Bereich des embryonalen Vorderdarms, dem Pankreasendoderm, entstehen, könnte es eine gemeinsame bipotente Vorläuferzelle geben. Diese Zelle und die für die Pankreasentwicklung spezifischen Signale zu identifizieren ist das Ziel von Frau Spagnoli, da eine solche Vorläuferzelle die Betazellherstellung in vitro vereinfachen könnte.

\section{Körperzellen als Ersatz für embryonale Zellen}

Im Gegensatz zu adulten Vorläuferzellen können embryonale Stammzellen nicht nur bestimmte Gewebe sondern auch einen ganzen Organismus bilden. Daher werden sie unabhängig von ethischen Bedenken zur Herstellung von Geweben genutzt. Frau Dr. Insa Schroeder von der Martin-Luther-Universität
Halle versucht, die Erkenntnisse aus der Erforschung der Pankreasentwicklung bei Mausstammzellen anzuwenden, um ein effektives Differenzierungsprotokoll zu etablieren. Allerdings gelingt eine reproduzierbare Differenzierung von embryonalen Mausstammzellen in Betazellen in vitro aktuell erst bis zum Pankreasendoderm. Um ethische Bedenken zu umgehen, überexprimieren Forscher mittels viralem Gentransfer meist vier Faktoren (OCT4, SOX2, KLF4 und c-Myc) in adulten menschlichen Körperzellen. Dies reicht, um Phänotypen mit dem pluripotenten Charakter embryonaler Stammzellen (iPS) zu induzieren. 2007 wurden erstmals ethisch unbedenkliche menschliche iPS (kein Embryoneneinsatz!) aus Fibroblasten generiert (Cell. Yu et al. Science; Takahshi et al.). Frau Schroeder stellte einen nicht viralen Ansatz zum Gentransfer und erste Ergebnisse zur Generierung krankheitsspezifischer iPS aus Körperzellen von Diabetikern mit genetischer Disposition vor. Gelingt die Differenzierung dieser iPS bis zur Betazelle, ist es möglich über den Vergleich mit normalen Betazellen wichtige molekulargenetische Informationen über die Diabetesentstehung zu erhalten.

\section{Alternative Strategien}

Eine Alternative beim therapeutischen Einsatz von Vorläuferzellen liegt in der gemeinsamen Transplantation von MSC und isolierten Pankreasinseln bei der klinischen Inseltransplantation. Diese ist, weil minimalinvasiv, für Patienten attraktiv, doch oft wächst aufgrund von Abstoßung, zellulärem Stress und zu langsamer Gefäßneubildung nur wenig des Materials an. Tiermodelle zeigen, daß kotransplantierte MSC über Aktivierung von Tregs die AbstoBung reduzieren und durch sezernierte proangiogene Faktoren (z.B. VEGF) die Gefäßneubildung verbessern. Daten der eigenen Arbeitsgruppe belegen, dass bislang unbekannte Substanzen aus MSC, unabhängig von Immunsystem und Angiogenese, zellulären Stress bei isolierten Inselzellen in vitro reduzieren können. Ein Ziel liegt in der Identifikation dieser Substanzen, da sie potenzielle Therapeutika sind.

Dr. Günther Päth, Freiburg

Quelle:,AKROBAT \& 10th German Islet Workshop

Freiburg, März 2011

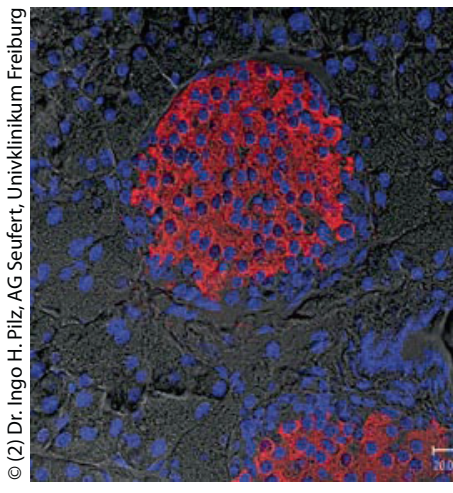

Abb. 1: Murine Pankreasinseln im konfokalen Mikroskop: Erkennbar sind die mithilfe einer Insulinfärbung rot hervorgehobenen Betazellen.

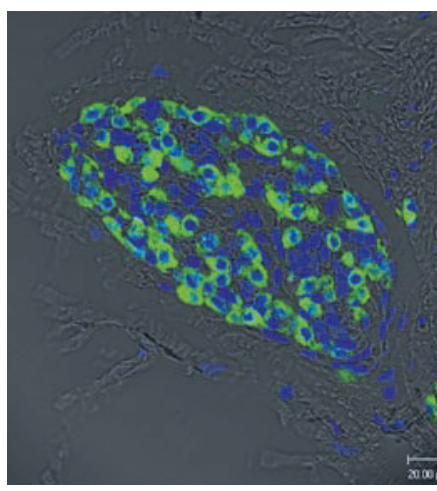

Abb. 2: In dieser Pankreasinsel eines Menschen sind die Alfazellen mit einer Glukagonfärbung grün gekennzeichnet. 